SUBJECT AREAS:

PATTERN FORMATION

DEVELOPMENT OF THE NERVOUS

SYSTEM

BIOPHYSICS

ANIMAL BEHAVIOUR

SCIENTIFIC REPORTS:

$2: 312$

DOI: $10.1038 /$ srep003 12

(2012)

Published:

15 March 2012

Updated:

18 February 2013

\section{CORRIGENDUM: Fetal Radiofrequency Radiation Exposure From 800-1900 Mhz-Rated Cellular Telephones Affects Neurodevelopment and Behavior in Mice}

\author{
Tamir S. Aldad, Geliang Gan, Xiao-Bing Gao \& Hugh S. Taylor
}

The authors identified an error in the determination of the maternal corticosterone levels as presented in Figure 4. The ELISA was repeated using stored serum samples from the original experiment. The levels have been corrected and are shown below in Figure 1 (the revised Figure 4). The mean corticosterone level in the pregnant control females was $5.4 \mathrm{ng} / \mathrm{ml}$ and in the exposed female mice was $6.1 \mathrm{ng} / \mathrm{ml}$. There was no significant difference between the corticosterone levels of the control and experimental groups. The correction does not change the conclusions.

Detailed Methods are included below and the full dataset has been uploaded as supplementary information (Supplementary Information accompanies this paper at http://www.nature.com/scientificreports).

\section{Methods}

Six pregnant controls and 6 exposed mice were sacrificed at day 12 of gestation in a $\mathrm{CO} 2$ chamber and blood was immediately collected from the heart. Blood was allowed to clot by leaving it undisturbed at room temperature (for 20 minutes). The clot was removed by centrifugation at $1200 \mathrm{~g}$ for 10 minutes at $4^{\circ} \mathrm{C}$ leaving the resulting supernatant (serum). The sample concentration was immediately determined by a corticosterone ELISA kit from Enzo Life Sciences (Farmingdale, NY 11735, product \# ADI-900-097). All samples were tested in duplicate and compared to a standard curve ranging from $0-20,000 \mathrm{pg} / \mathrm{ml}$ (provided by the manufacturer). The assay's lowest level of sensitivity is described as $27 \mathrm{pg} / \mathrm{ml}$.

Specifically, $100 \mu \mathrm{l}$ of the standards in the provided diluents were pipette in duplicate into a 96 well plate. Similarly $100 \mu l$ of the unknowns were pipette into the plate. The appropriate assay buffers were added as per the manufacturer's instructions and the plate was incubated at room temperature for 2 hours while shaking. This was followed by washes using the buffer provided by the ELISA kit as recommended by the manufacturer.

After the final wash, $5 \mu \mathrm{l}$ of the conjugate for total activity was added to the appropriate wells whereas $200 \mu \mathrm{l}$ of (p-nitrophenyl phosphate) pNpp substrate was added to all wells. The plate was incubated for 1 hour without shaking.

The reaction was stopped by adding $50 \mu \mathrm{l}$ of stop solution and the plate was immediately read at $405 \mathrm{~nm}$ after subtraction of the blanks, with an automated ELISA reader from Molecular Devices (Sunnyvale, California). The values were plotted in a semilogarithmic inverse fashion as this is a competitive assay and concentrations determined in the samples using the formula: $\log$ conc $=\mathrm{y}$ intercept + slope $\mathrm{x} O D$. For this calculation we used the PRISM Graph Pad program (La Jolla, CA).

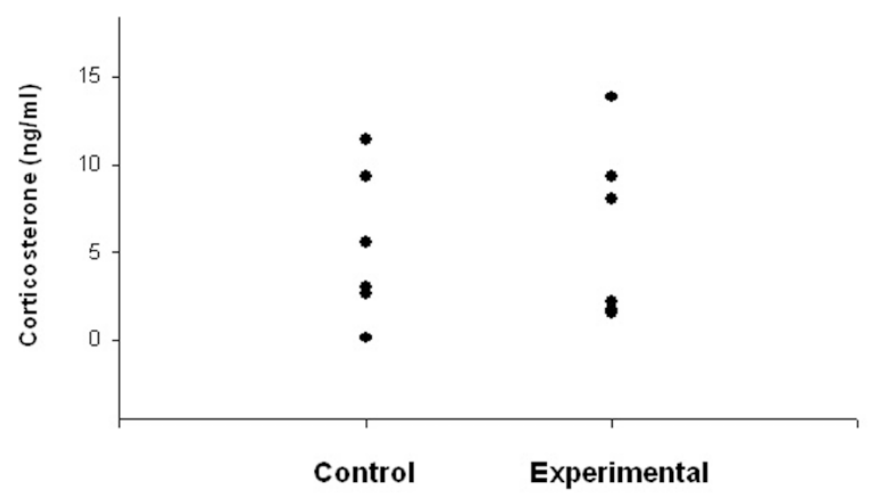

Figure 1 Corticosterone levels during pregnancy were unaltered by exposure. Corticosterone levels were measured on pregnant mice on day 12 of gestation. The mean corticosterone levels in pregnant control mice was $5.4 \mathrm{ng} / \mathrm{ml}$ and in exposed pregnant mice was $6.1 \mathrm{ng} / \mathrm{ml}$. The differences were not statistically significant $(\mathrm{P}=0.786$ by $\mathrm{T}$ test $)$. Twelve representative mice housed separately were used, six from each exposure group. 